\title{
Promoter methylation and expression changes of $B R C A 1$ in cancerous tissues of patients with sporadic breast cancer
}

\author{
QIUYUN LI ${ }^{1,2^{*}}$, WEI WEI ${ }^{1 *}$, YI JIANG ${ }^{1}$, HUAWEI YANG ${ }^{1}$ and JIANLUN LIU ${ }^{1}$ \\ ${ }^{1}$ Department of Breast Surgery, The Affiliated Tumor Hospital of Guangxi Medical University; \\ ${ }^{2}$ Department of General Surgery, No. 303 Hospital of PLA, Nanning, Guangxi 530021, P.R. China
}

Received April 14, 2014; Accepted January 13, 2015

DOI: 10.3892/ol.2015.2908

\begin{abstract}
B R C A 1$ is a susceptibility gene that has a genetic predisposition for breast cancer. $B R C A 1$ gene mutation is closely associated with familial hereditary breast cancer, but the $B R C A 1$ gene mutation is rarely found in sporadic breast cancer. According to previous studies, decreased expression of $B R C A I$ was detected in certain types of sporadic breast cancer. Aberrant methylation of DNA promoter $\mathrm{CpG}$ islands is one of the mechanisms by which tumor suppressor gene expression and function is lost. The aim of the present study was to investigate $B R C A 1$ gene expression, methylation status and clinical significance in sporadic types of breast cancer. Quantitative polymerase chain reaction (PCR) and bisulfite sequencing PCR were respectively used to detect expression differences of BRCA1 mRNA and BRCA1 methylation in the 49 cancerous and paired non-cancerous samples from patients with breast cancer. The associations of $B R C A 1$ expression and methylation status with the clinicopathologic characteristics were analysed. BRCA1 mRNA expression levels in the 49 breast cancer tissues were lower than those in the paired non-cancerous tissues. There was a significant statistical difference $(\mathrm{P}=0.001)$. BRCAI mRNA expression was not associated with the main clinicopathologic characteristics. Frequency of the BRCAl promoter methylation in the breast cancerous tissues was significantly higher than that in the non-cancerous tissues $(\mathrm{P}=0.007) ; B R C A 1$ gene methylation status was negatively correlated with mRNA expression ( $\mathrm{P}=0.029)$; and $B R C A 1$ methylation exhibited no association with all clinicopathological features. DNA promoter hypermethylation may be the potential mechanism accounting for $B R C A 1$ expression silence in part of sporadic types of breast cancer. Some patients with hypermethylated $B R C A 1$ may display favorable clinicopathological status.
\end{abstract}

Correspondence to: Dr Jianlun Liu, Department of Breast Surgery, The Affiliated Tumor Hospital of Guangxi Medical University, 71 He Ti Road, Nanning, Guangxi 530021, P.R. China

E-mail: jianlunliu@hotmail.com

"Contributed equally

Key words: breast cancer, BRCA1, DNA methylation

\section{Introduction}

$B R C A 1$, breast cancer susceptibility gene 1 , maps to $17 \mathrm{q} 21$ (1) and encodes a multifunctional protein involved in DNA repair (2), control of cell-cycle checkpoints (3), ubiquitinylation and chromatin remodeling (4). BRCAl was originally identified and cloned as a predisposition gene of familial breast cancer in 1994 (5). Although a significant fraction of familial types of breast cancer could be explained by the inherited mutations of BRCA1, a large proportion of familial and sporadic types of breast cancer are not associated with mutations in BRCAl (6-9) Furthermore, BRCA1 mRNA levels were also found to be reduced or absent in invasive sporadic types of breast cancer, thus assigning a role of BRCAl in these as well (10-12). This suggests that other mechanisms for loss of functions may exist.

Breast cancer results from the manifestation of genetic and epigenetic changes in tumor suppressor genes and oncogenes $(13,14)$. Although the causal association remains under debate, increasing evidence has shown that hypermethylation of promoter $\mathrm{CpG}$ islands $(15,16)$, accompanied by global hypomethylation $(17,18)$, are common molecular events in cancer cells. Promoter $\mathrm{CpG}$ islands, which frequently locate at the 5 ' end regulatory regions of genes, are subject to epigenetic modification by DNA methylation which is known to play an important role in regulating gene expression $(16,19)$. If promoter $\mathrm{CpG}$ islands of key genes were hypermethylated and form a closed repressive chromatin configuration, the transcription initiation of the corresponding genes should be affected (20).

There are reports that $B R C A 1$ promoter methylation status is associated with downregulated mRNA and protein levels in breast cancerous tissues $(21,22)$ and cell lines $(23)$. Aberrant $B R C A 1$ promoter methylation is associated with particular biological and clinicopathological features $(24,25)$. However, these studies failed to lead to a conclusive finding. In the current study, the hypothesis is that the absence of BRCAl transcript is associated with promoter methylation in sporadic types of breast cancer. The present study further investigates $B R C A 1$ gene expression, methylation status and their clinical significance in sporadic breast cancer.

\section{Materials and methods}

Study cohort and tissue samples. The study was approved by the ethics committee of Guangxi Medical University (Nanning, 
Table I. Primer sequences used in the study.

\begin{tabular}{ll}
\hline Gene/primer & Sequence \\
\hline BRCAl & \\
Forward & TGTGAGGCACCTGTGGTGAC \\
Reverse & GTGGCTGGCTGCAGTCAGTAG \\
$\beta$-catenin & GAAACGGCTTTCAGTTGAGC \\
Forward & CTGGCCATATCCACCAGAGT \\
Reverse & \\
Bisulfite sequencing primer & GATTGGGTGGTTAATTTAGAGT \\
Forward & AATTATCTAAAAAACCCCACAA \\
Reverse & \\
\hline
\end{tabular}

China). All patients involved in the study provided their informed consent. The study cohort consisted of 49 patients, who were randomly selected from patients continuously diagnosed with operable breast cancer between September 2010 and September 2012 in the Department of Breast Surgery of the Affiliated Tumor Hospital of Guangxi Medical University. Patients were excluded from participation in the case of familial types of breast cancer; prior chemotherapy or radiotherapy for any malignancy; and pregnancy or lactation.

All the studied samples included 49 surgically resected cancerous tissues and 49 corresponding paired non-cancerous tissues which were taken $>5 \mathrm{~cm}$ from the tumor macroscopically (in cases where such distance was not present, the non-cancerous sample was taken from the distance furthest from the tumor sample). These samples were the fresh tissues following surgical removal, and were immediately put into liquid nitrogen for $10 \mathrm{~min}$ and then into a $-80^{\circ} \mathrm{C}$ ultra freezer. All samples were subsequently reviewed and confirmed by the Department of Pathology of the Affiliated Tumor Hospital of Guangxi Medical University. Pathological information was collected from the patient clinical database, and the information was blinded in another database. The clinicopathologic characteristics of patients included histological tumor type, primary tumor size, axillary nodal status, grade of the disease, estrogen/progesterone receptor (ER/PR) status or HER-2/neu status.

RNA extraction and quantitative polymerase chain reaction $(P C R)$. The RNA isolated from the breast cancerous tissues and paired non-cancerous tissues were kept using TRIzol ${ }^{\circledR}$ reagent (Invitrogen Life Technologies, Carlsbad, CA, USA) according to the manufacturer's instructions. $\beta$-actin mRNA was the reference gene used as the internal control. The primers of $B R C A 1$ and $\beta$-actin (Invitrogen Life Technologies) are shown in Table I. The PCR cycle conditions used are $95^{\circ} \mathrm{C}$ for $2 \mathrm{~min}$; 40 cycles at $95^{\circ} \mathrm{C}$ for $10 \mathrm{sec}, 60^{\circ} \mathrm{C}$ for $30 \mathrm{sec}$, and $70^{\circ} \mathrm{C}$ for $30 \mathrm{sec}$; and final extension at $72^{\circ} \mathrm{C}$ for $7 \mathrm{~min}$. Dissociation curve analyses were used to confirm the specificity of the SYBR ${ }^{\circledR}$ Green (Invitrogen Life Technologies) signals in each experiment. Data were analyzed using ABI Prism 7900 SDS software (Applied Biosystems, Waltham, MA, USA). The mRNA expression of BRCAl was analyzed using the $2^{-\Delta \Delta C t}$ method (26). Fluorescent data were converted into RQ measurements, which stand for relative expression automated by the system software. Thermal dissociation plots were examined for biphasic melting curves. To ensure experiment accuracy, quantitative PCR products were randomly selected for sequencing.

DNA extraction and sodium bisulfite modification. Total genomic DNA of the specimens were isolated from the breast cancerous tissues and paired non-cancerous tissues, by the DNeasy Tissue AxyPrep DNA extraction kit (Tiangen, Beijing, China). All procedures were followed according to the manufacturer's instructions. Genomic DNA was modified with bisulfite using MethylCode ${ }^{\mathrm{TM}}$ Bisulfite Conversion kit (Invitrogen Life Technologies) according to the manufacturer's instructions.

Bisulfite genomic sequencing. Bisulfite genomic DNA sequencing was carried out as previously described (27) with sodium bisulfite modification. The $\mathrm{CpG}$ islands of promoter region located between -937 and -717 bp (translation start site as 1). The bisulfite-treated DNA was subjected to PCR in order to amplify the BRCAl promoter region. The primers of bisulfite genomic sequencing are shown in Table I. PCR products were purified and cloned into the pMD18-T vector (Takara, Dalian, China), then transformed into Escherichia coli strain DH5 $\alpha$ (Invitrogen Life Technologies). Five positive clones for each sample were selected and analyzed using the ABI 3730 DNA Sequencer (Applied Biosystems). The percentage of methylation for each sample was calculated as the number of methylated CpG dinucleotides / (5x48) x 100\%.

Statistical analysis. Statistical analysis was performed using SPSS software version 13.0 (SPSS, Inc., Chicago, IL, USA). Gene expression levels or DNA methylation status of paired samples with normal distribution were expressed as the mean \pm standard deviation; otherwise, they were expressed as the median with the first and third interquartile ranges (IQR1 and IQR3). Associations between BRCA1 mRNA expression or DNA methylation and the categorical variables were assessed by the Pearson's $\chi^{2}$ or Mann-Whitney U tests, as appropriate. Correlation coefficients were assessed by Spearman's correlation analysis. $\mathrm{P}<0.05$ was considered to indicate a statistically significant difference, and all P-values were two-sided. 
Table II. Correlations between BRCAl mRNA expression and the main clinicopathologic characteristics.

\begin{tabular}{|c|c|c|c|c|c|c|}
\hline \multirow[b]{2}{*}{ Variable } & \multirow[b]{2}{*}{$\mathrm{n}$} & \multicolumn{4}{|c|}{$B R C A 1$ mRNA expression } & \multirow[b]{2}{*}{ P-value } \\
\hline & & Reduced & $\%$ & Overexpression & $\%$ & \\
\hline Age (years) & & & & & & $0.304^{\mathrm{a}}$ \\
\hline$<50$ & 28 & 19 & 67.9 & 9 & 32.1 & \\
\hline$\geq 50$ & 21 & 17 & 81.0 & 4 & 19.0 & \\
\hline Menopause & & & & & & $0.129^{\mathrm{a}}$ \\
\hline Pre & 29 & 19 & 65.5 & 10 & 34.5 & \\
\hline Post & 20 & 17 & 85.0 & 3 & 15.0 & \\
\hline TNM stage & & & & & & $0.078^{\mathrm{b}}$ \\
\hline I & 9 & 5 & 55.6 & 4 & 44.4 & \\
\hline II & 24 & 17 & 70.8 & 7 & 29.2 & \\
\hline III & 16 & 14 & 87.5 & 2 & 12.5 & \\
\hline ER & & & & & & $0.219^{\mathrm{a}}$ \\
\hline Negative & 14 & 12 & 85.7 & 2 & 14.3 & \\
\hline Positive & 35 & 24 & 68.6 & 11 & 31.4 & \\
\hline $\mathrm{PR}$ & & & & & & $0.232^{\mathrm{a}}$ \\
\hline Negative & 22 & 18 & 81.9 & 4 & 18.2 & \\
\hline Positive & 27 & 18 & 66.7 & 9 & 33.3 & \\
\hline HER-2/neu & & & & & & $0.156^{\mathrm{a}}$ \\
\hline Negative & 34 & 27 & 79.4 & 7 & 20.6 & \\
\hline Positive & 15 & 9 & 60.0 & 6 & 40.0 & \\
\hline Ki-67 & & & & & & $0.492^{\mathrm{a}}$ \\
\hline$<0.15$ & 15 & 12 & 80.0 & 3 & 20.0 & \\
\hline$\geq 0.15$ & 34 & 24 & 70.6 & 10 & 29.4 & \\
\hline Axillary nodes & & & & & & $0.682^{\mathrm{a}}$ \\
\hline Negative & 24 & 17 & 70.8 & 7 & 29.2 & \\
\hline Positive & 25 & 19 & 76.0 & 6 & 24.0 & \\
\hline Tumor stage & & & & & & $0.140^{\mathrm{b}}$ \\
\hline $\mathrm{T} 1$ & 6 & 3 & 50.0 & 3 & 50.0 & \\
\hline $\mathrm{T} 2$ & 25 & 18 & 72.0 & 7 & 28.0 & \\
\hline $\mathrm{T} 3$ & 12 & 10 & 83.3 & 2 & 16.7 & \\
\hline $\mathrm{T} 4$ & 6 & 5 & 83.3 & 1 & 16.7 & \\
\hline
\end{tabular}

${ }^{\text {aP }}$-value when expression levels were compared using the Pearson's $\chi^{2}$ test. ${ }^{\text {bP }}$-value when expression levels were compared using the Mann-Whitney U test. TNM, tumor, node and metastasis; ER, estrogen receptor; PR, progesterone receptor.

\section{Results}

Expression of BRCAl in breast cancerous and paired non-cancerous samples. In the present study, the median level of BRCAl in non-cancerous samples was set as 1 . The median RQs of BRCA1 mRNA in breast cancerous and paired non-cancerous samples were 0.33 (IQR1, 0.18; IQR3, 0.95) and 0.94 (IQR1, 0.46; IQR3, 1.98), respectively. The difference between the two group was statistically significant (Wilcoxon matched-pairs signed-ranks test, $\mathrm{P}=0.001$ ). The representative results of the quantitative PCR are provided in Fig. 1. The results indicate that the expression of $B R C A l$ in breast cancer was aberrantly decreased at the transcriptional level.

According to the median RQ of the paired non-cancerous tissues which was 0.94 , the tumor tissues were divided into three groups: overexpression $(>0.94)$, normal expression $(=0.94)$ and reduced expression $(<0.94)$. Due to the limited number of tissues in the over and normal expression groups, these two groups were combined into one group, named the unreduced expression group. The correlation between BRCAl mRNA and the main clinicopathologic characteristics was also analyzed. The associations between them are shown in Table II. No significant correlation was observed between BRCAl mRNA and the various parameters.

Correlation of BRCA1 expression and methylation in breast cancerous and paired non-cancerous samples. Analysis was carried out using the Methyl Primer Express version 1.0 (Applied Biosystems) to analyze the $\mathrm{CpG}$ islands of the region between $-2,000$ and $+1,000 \mathrm{bp}$, including the translational 


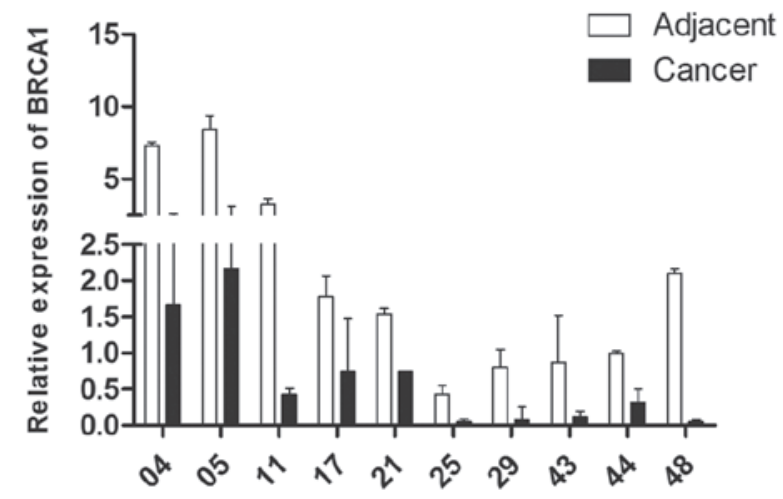

Figure 1. Relative expression of $B R C A 1$ in breast cancer and paired adjacent non-cancerous samples from the selected patients. $B R C A 1$ expression was expressed as the $2^{-\Delta \Delta C T}$.

initiation codon (ATG) in detail. In the 5 ' end of the BRCAI gene, two $\mathrm{CpG}$ islands were revealed, a 244 bp (between $-1,279$ and $-1,036 \mathrm{bp}$ ) and a $221 \mathrm{bp}$ (between -937 and $-717 \mathrm{bp}$ ) segment (Fig. 2).

To determine whether epigenetic silencing of the BRCAI gene also occurs in primary breast cancer, the BRCAl methylation status in 49 paired breast cancer and corresponding non-cancerous tissues was examined (Fig. 3). Aberrant hypermethylation was detected in 24 of 49 (49\%) tumors, which was more frequent than that in the paired no-cancerous tissues (11 of 49, 22.4\%; Wilcoxon matched-pairs signed-ranks test, $\mathrm{P}=0.007)$. In 24 cases of hypermethylation of cancerous tissues, 20 (83.3\%) showed a lower BRCA1 mRNA expression. Furthermore, it was revealed that the association between BRCA1 mRNA expression level and methylation status was a negative correlation $(\mathrm{r}=-0.311, \mathrm{P}=0.029)$, which indicated a correlation between $\mathrm{CpG}$ island hypermethylation and transcriptional silencing.

Association between BRCA1 methylation level in breast cancer and the main clinicopathological parameters. To ascertain the potential clinical significance of the epigenetic event, analysis was conducted on the main clinicopathological characters and methylation status of BRCA1 in the 49 cases. The associations between $B R C A 1$ methylation status and various clinicopathological parameters are shown in Table III. No significant correlation was observed between BRCAI hypermethylation and main parameters such as age at diagnosis, menopausal status, tumor, node and metastasis (TNM) stage, primary tumor size, axillary nodal status, ER/PR status or HER-2/neu status.

\section{Discussion}

$B R C A 1$ is a well-established breast cancer susceptibility gene, and is involved in maintaining genome integrity through pathways including participation in DNA damage repair, the control of cell cycle checkpoints and apoptosis (2-4). In these functions, $B R C A 1$ is implicated in the repair of double strand DNA breaks by homologous chromosomal recombination $(28,29)$. Deficiencies in homology-directed DNA repair cause high levels of genomic instability that increases the risk of tumorigenesis (30). BRCAl that impairs such function leads to increased proliferation and chromosomal instability. It has been proved that BRCA1 mutation is one of the main genetic events in the hereditary type of breast cancer (6), but no or limited somatic mutations in $B R C A l$ have been found in the sporadic form of breast cancer. On the another hand, a growing number of studies have demonstrated loss of heterozygosity and a reduced level or absence of BRCAl expression in sporadic breast cancer $(31,32)$. These two factors suggest that transcriptional and/or posttranscriptional repression of $B R C A 1$ may participate in the development of sporadic breast cancer. One of the common mechanisms of functional inactivation of tumor suppressor genes in cancer cells is the aberrant DNA hypermethylation of $\mathrm{CpG}$ islands in the promoter region of the gene that is associated with the loss of gene expression.

Firstly, BRCAl expression at the mRNA level was detected in paired cancerous and non-cancerous tissue of sporadic breast cancer. BRCAI expression of breast cancerous tissues showed a relatively lower level as compared with those of the paired non-cancerous tissues. The difference between them was statistically significant. The data indicated that the expression of BRCAl in breast cancer was aberrantly reduced. Subsequently, the present study demonstrated that the low expression of $B R C A l$ was significantly correlated with the hypermethylation in its promoter region. In the present study, $B R C A 1$ hypermethylation was detected in $49 \%$ of the cases, which was consistent with other previous reports (9.1 59\%) (33-35). The differences in the frequency of hypermethylation among the studies may be accounted for by several factors including: Methodology, study cohort, adjacent non-cancerous tissues contaminated by cancer cells and population differences due to exposure to specific environmental factors.

Furthermore, the correlation between $B R C A 1$ hypermethylation and the main clinicopathological characters was analyzed. Ever since $B R C A l$ hypermethylation was proved to be involved in sporadic breast cancer, some studies were dedicated to explore the correlation between its aberrant methylation and the disease characteristics. BRCAl promoter methylation status displayed various disease characteristic phenotypes in different studies; however, the majority of studies demonstrated that BRCAl hypermethylation correlated with lack of estrogen and progesterone receptor expression in younger females ( $<50$ years). Nevertheless, the present study did not discover a significant association between BRCAl hypermethylation and ER/PR status. This result was similar to that reported in a previous study by Xu et al (36). Furthermore, in the study by Matros et al (37), they even found that BRCAl hypermethylation is correlated with progesterone receptor positive expression, suggesting a more complex phenotypic association.

In addition, two interesting details were revealed which may be associated with favorable clinical prognosis, though there was no association between $B R C A 1$ hypermethylation and the main clinicopathological characters including age at diagnosis, menopausal status, TNM stage, primary tumor size, axillary nodal status, ER/PR status or HER-2/neu status in sporadic breast cancer. Firstly, the $B R C A l$ hypermethylation exhibited a higher percentage of the smaller size primary tumor (T1 and T2, tumor size $\leq 5 \mathrm{~cm}$ ) compared to the BRCA1 non-methylation ( $58.1 \%$ vs. $49.1 \%$ ). The result seemed to display a trend that $B R C A 1$ hypermethylation tumors tended to 


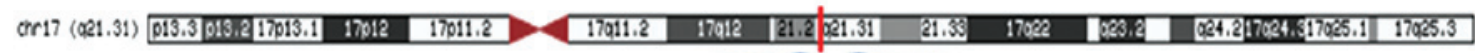

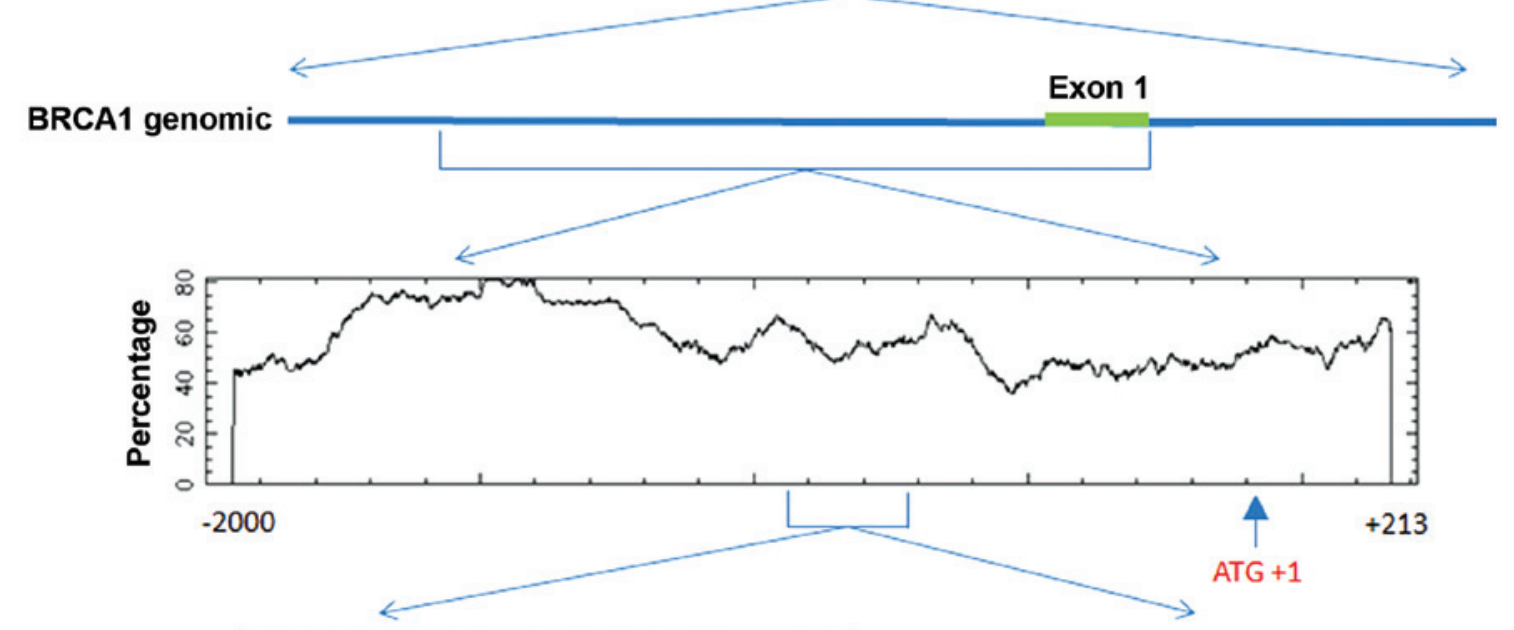

TAACCCAGGCTGCTTCCTTACCAGCTTCCCGCCCCCTGGGGAGGCGGCAA TGCAAAGACCGTCCGCTGCCAGCTCTGCCGCTATCTCTGTGGGGTGAATCT AACATGGCGGACAAAGACAGTAACTAGTCCCGTTTCTCCGCGTTTTCGCC AAGAAGATTGGCTCTTACCACTTGTCCCTCAAAACGACCACCCCATTGACT GGTGGCGATTGCGICGACGGAGACGGGGCAAAAGCAAGCTGAACCCGAA AAATAACAAACACTGGGGCTG

Figure 2. Genomic architecture of the human BRCA1 gene. (A) Location of the BRCA1 gene within human chromosome 17 (ch17 q21.31); (B) exon/intron structure of the human BRCA1 gene. Noted is the relative location of the first 1 coding exons and the translational start (ATG) codons. (C) Structure of 5' end of BRCAl gene. Graph of percent guanine (G) and cytosine (C) nucleotides across this region and boundaries of the CpG island. (D) Detailed information of the $B R C A 1$ promoter region sequence. The bisulfite sequencing polymerase chain reaction primers are presented in the green shaded region. There are $14 \mathrm{CpG}$ sites in this region.

A

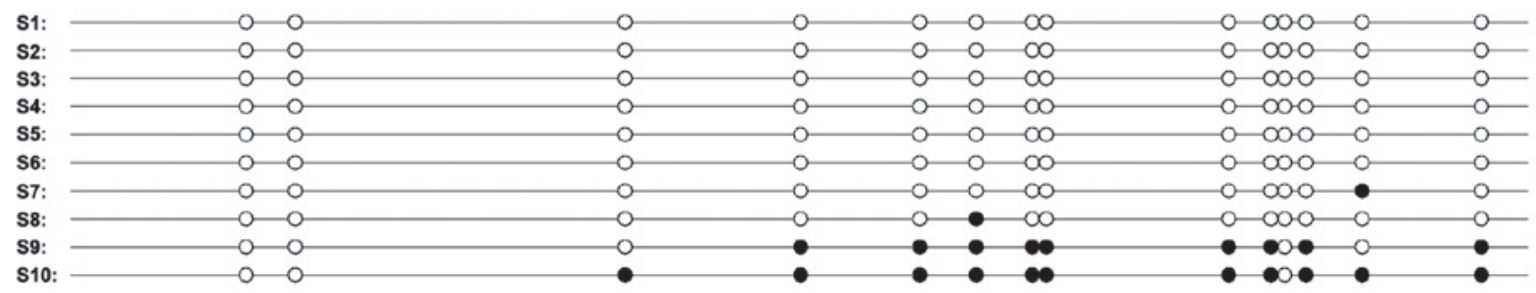

$\mathbf{B}$

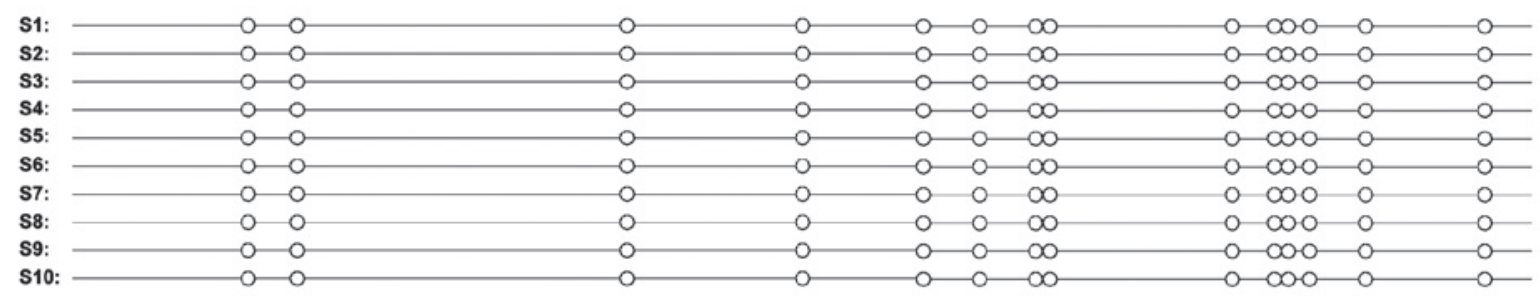

C

D

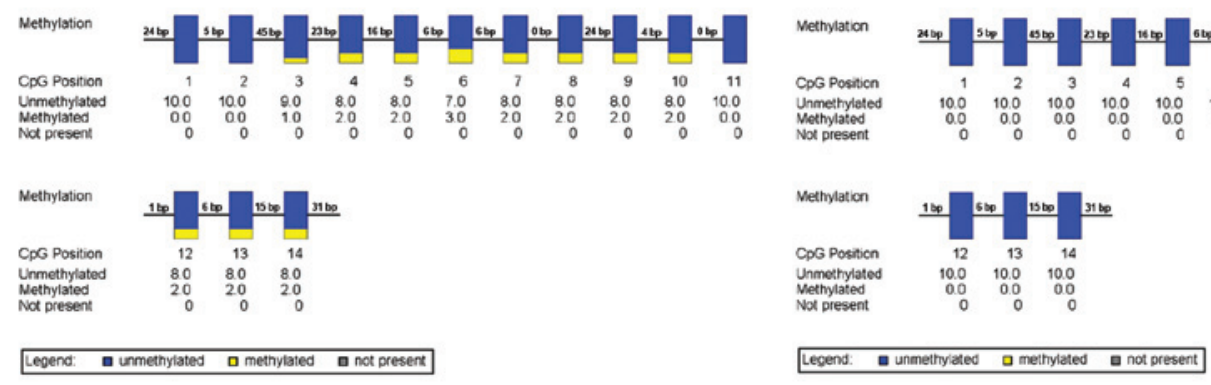

Figure 3. Methylation status analysis of $B R C A 1$ in breast cancer. BSP methylation status analysis of $B R C A 1$ in (A) breast cancer and (B) non-cancerous tissues; Sulfite process BSP sequencing mode of $B R C A 1$ in (C) breast cancer and (D) non-cancerous tissues. BSP, bisulfite sequencing polymerase chain reaction. 
Table III. Correlations between BRCAl methylation status and the main clinicopathological characteristics.

\begin{tabular}{|c|c|c|c|c|c|c|}
\hline \multirow[b]{2}{*}{ Variable } & \multirow[b]{2}{*}{$\mathrm{n}$} & \multicolumn{4}{|c|}{ BRCAl methylation status } & \multirow[b]{2}{*}{ P-value } \\
\hline & & Reduced & $\%$ & Overexpression & $\%$ & \\
\hline Age & & & & & & $0.458^{\mathrm{a}}$ \\
\hline$<50$ & 28 & 13 & 46.4 & 15 & 53.6 & \\
\hline$\geq 50$ & 21 & 12 & 57.1 & 9 & 42.9 & \\
\hline Menopause & & & & & & $0.644^{\mathrm{a}}$ \\
\hline Pre & 29 & 14 & 48.3 & 15 & 51.7 & \\
\hline Post & 20 & 11 & 55.0 & 9 & 45.0 & \\
\hline TNM stage & & & & & & $0.465^{\mathrm{b}}$ \\
\hline I stage & 9 & 4 & 44.4 & 5 & 55.6 & \\
\hline II stage & 24 & 15 & 62.5 & 9 & 37.5 & \\
\hline III stage & 16 & 6 & 37.5 & 10 & 62.5 & \\
\hline ER & & & & & & $0.470^{\mathrm{a}}$ \\
\hline Negative & 14 & 6 & 42.9 & 8 & 57.1 & \\
\hline Positive & 35 & 19 & 54.3 & 16 & 45.7 & \\
\hline PR & & & & & & $0.201^{\mathrm{a}}$ \\
\hline Negative & 22 & 9 & 40.9 & 13 & 59.1 & \\
\hline Positive & 27 & 16 & 59.3 & 11 & 40.7 & \\
\hline HER-2/neu & & & & & & $0.686^{\mathrm{a}}$ \\
\hline Negative & 34 & 18 & 52.9 & 16 & 47.1 & \\
\hline Positive & 15 & 7 & 46.7 & 8 & 53.3 & \\
\hline Ki-67 & & & & & & $0.086^{\mathrm{a}}$ \\
\hline$<0.15$ & 15 & 6 & 40.0 & 9 & 60.0 & \\
\hline$\geq 0.15$ & 34 & 19 & 55.9 & 15 & 44.1 & \\
\hline Axillary nodes & & & & & & $0.666^{\mathrm{a}}$ \\
\hline Negative & 24 & 13 & 54.2 & 11 & 45.9 & \\
\hline Positive & 25 & 12 & 48.0 & 13 & 52.0 & \\
\hline Tumor stage & & & & & & $0.508^{\mathrm{b}}$ \\
\hline $\mathrm{T} 1$ & 6 & 2 & 33.3 & 4 & 66.7 & \\
\hline $\mathrm{T} 2$ & 25 & 11 & 44.0 & 14 & 56.0 & \\
\hline $\mathrm{T} 3$ & 12 & 9 & 75.0 & 3 & 25.0 & \\
\hline $\mathrm{T} 4$ & 6 & 3 & 50.0 & 3 & 50.0 & \\
\hline
\end{tabular}

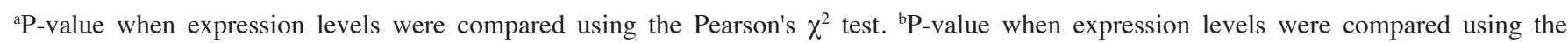
Mann-Whitney U test. TNM, tumor, node and metastasis; ER, estrogen receptor; PR, progesterone receptor.

be the smaller tumor size. The larger size of tumor is one of the most important indicators for poor prognosis. Secondly, there was more $B R C A 1$ hypermethylation of low $\mathrm{Ki}-67$ index $(<15 \%)$ cancerous tissues compared with the BRCAl non-methylation (60\% vs. $40 \%)$. The high Ki-67 index ( $\geq 15 \%)$, which is one of the important parameters for luminal phenotype, has been proven to correlate with a greater carcinogenic aggressiveness and worse prognosis. The reasons underlying the phenomenon of BRCA1 methylation were not elucidated, but some evidence was found correlating $B R C A 1$ hypermethylation and favorable disease characteristics in a study by Li et al (38). On the basis of a smaller sample the study demonstrated high survival rates associated with BRCAl hypermethylation. Krasteva et al (39) also reported that breast cancer with $B R C A l$ hypermethylation was associated with improved overall survival rates. Those evidences may partly explain the present findings. Following cautious consideration, the findings from the present study do not appear to be contradictory to previous studies. By contrast, the present study results once again manifested that breast cancer was a type of heterogeneous disease from one aspect.

In conclusion, the present study revealed that BRCAI expression was expressed at low levels in the majority of sporadic breast cancerous tissues, and DNA promoter hypermethylation may be the potential mechanism accounting for $B R C A 1$ expression silence. Secondly, the reduced BRCAI expression and $B R C A 1$ hypermethylation did not correlate with any clinicopathological features. Finally, partial sporadic breast cancer with $B R C A l$ hypermethylation may exhibit 
favorable clinicopathological status. It is thus reasonable to explore $B R C A 1$ epigenetic inactive mechanism and identify a subset of sporadic breast cancer with a specific epigenetic phenotype. Further studies to observe whether a specific BRCA1-related sporadic breast cancer can indicate a favorable prognosis would be beneficial.

\section{Acknowledgements}

This study was supported by funds from the Natural Scientific Foundation of Guangxi (no. 2011GXNSFB018102).

\section{References}

1. Hall JM, Lee MK, Newman B, et al: Linkage of early-onset familial breast cancer to chromosome $17 \mathrm{q} 21$. Science 250 1684-1689, 1990

2. Deng CX and Wang RH: Roles of BRCAl in DNA damage repair: a link between development and cancer. Hum Mol Genet 12 Spec No 1: R113-R123, 2003.

3. Xu B, St K and Kastan MB: Involvement of BRCAl in S-phase and $\mathrm{G}(2)$-phase checkpoints after ionizing irradiation. Mol Cell Biol 21: 3445-3450, 2001

4. Ralhan R, Kaur J, Kreienberg R and Wiesmüller L: Links between DNA double strand break repair and breast cancer: accumulating evidence from both familial and nonfamilial cases. Cancer Lett 248: 1-17, 2007.

5. Miki Y, Swensen J, Shattuck-Eidens D, et al: A strong candidate for the breast and ovarian cancer susceptibility gene BRCAI. Science 266: 66-71, 1994.

6. Easton DF, Bishop DT, Ford D and Crockford GP: Genetic linkage analysis in familial breast and ovarian cancer: results from 214 families. The Breast Cancer Linkage Consortium. Am J Hum Genet 52: 678-701, 1993.

7. Narod SA, Ford D, Devilee P, et al: An evaluation of genetic heterogeneity in 145 breast-ovarian cancer families. Breast Cancer Linkage Consortium. Am J Hum Genet 56: 254-264, 1995.

8. Ford D, Easton DF, Stratton M, et al: Genetic heterogeneity and penetrance analysis of the $B R C A 1$ and $B R C A 2$ genes in breast cancer families. The Breast Cancer Linkage Consortium. Am J Hum Genet 62: 676-689, 1998.

9. Hedenfalk I, Ringner M, Ben-Dor A, et al: Molecular classification of familial non-BRCA1/BRCA2 breast cancer. Proc Natl Acad Sci USA 100: 2532-2537, 2003.

10. Thompson ME, Jensen RA, Obermiller PS, Page DL and Holt JT: Decreased expression of $B R C A 1$ accelerates growth and is often present during sporadic breast cancer progression. Nat Genet 9: 444-450, 1995.

11. Magdinier F, Ribieras S, Lenoir GM, Frappart L and Dante R: Down-regulation of $B R C A 1$ in human sporadic breast cancer; analysis of DNA methylation patterns of the putative promoter region. Oncogene 17: 3169-3176, 1998.

12. Bianco T, Chenevix-Trench G, Walsh DC, Cooper JE and Dobrovic A: Tumour-specific distribution of $B R C A 1$ promoter region methylation supports a pathogenetic role in breast and ovarian cancer. Carcinogenesis 21: 147-151, 2000.

13. Jones PA and Baylin SB: The fundamental role of epigenetic events in cancer. Nat Rev Genet 3: 415-428, 2002

14. Franco R, Schoneveld O, Georgakilas AG and Panayiotidis MI: Oxidative stress, DNA methylation and carcinogenesis. Cancer Lett 266: 6-11, 2008

15. Herman JG and Baylin SB: Gene silencing in cancer in association with promoter hypermethylation. N Engl J Med 349: 2042-2054, 2003 .

16. Das PM and Singal R: DNA methylation and cancer. J Clin Oncol 22: 4632-4642, 2004.

17. Feinberg AP and Vogelstein B: Hypomethylation distinguishes genes of some human cancers from their normal counterparts. Nature 301: 89-92, 1983.
18. Choi JY, James SR, Link PA, et al: Association between global DNA hypomethylation in leukocytes and risk of breast cancer. Carcinogenesis 30: 1889-1897, 2009.

19. Robertson KD: DNA methylation and chromatin-unraveling the tangled web. Oncogene 21: 5361-5379, 2002

20. Baylin SB and Ohm JE: Epigenetic gene silencing in cancer-a mechanism for early oncogenic pathway addiction. Nat Rev Cancer 6: 107-116, 2006.

21. Esteller M, Silva JM, Dominguez G, et al: Promoter hypermethylation and BRCA1 inactivation in sporadic breast and ovarian tumors. J Natl Cancer Inst 92: 564-569, 2000.

22. Birgisdottir V, Stefansson OA, Bodvarsdottir SK, Hilmarsdottir H, Jonasson JG and Eyfjord JE: Epigenetic silencing and deletion of the BRCAl gene in sporadic breast cancer. Breast Cancer Res 8: R38, 2006.

23. Rice JC, Massey-Brown KS and Futscher BW: Aberrant methylation of the $B R C A 1 \mathrm{CpG}$ island promoter is associated with decreased BRCA1 mRNA in sporadic breast cancer cells. Oncogene 17: 1807-1812, 1998.

24. Catteau A, Harris WH, Xu CF and Solomon E: Methylation of the $B R C A 1$ promoter region in sporadic breast and ovarian cancer: correlation with disease characteristics. Oncogene 18: 1957-1965, 1999

25. Turner N, Tutt A and Ashworth A: Hallmarks of 'BRCAness' in sporadic cancers. Nat Rev Cancer 4: 814-819, 2004.

26. Livak KJ and Schmittgen TD: Analysis of relative gene expression data using real-time quantitative PCR and the 2(-Delta Delta C(T)) Method. Methods 25: 402-408, 2001.

27. Chu D, Zhang Z, Li Y, et al: Prediction of colorectal cancer relapse and prognosis by tissue mRNA levels of NDRG2. Mol Cancer Ther 10: 47-56, 2011.

28. Zhang J and Powell SN: The role of the BRCA1 tumor suppressor in DNA double-strand break repair. Mol Cancer Res 3: 531-539, 2005.

29. Ting NS and Lee WH: The DNA double-strand break response pathway: becoming more BRCAish than ever. DNA Repair (Amst) 3: 935-944, 2004

30. De Vargas Roditi L and Michor F: Evolutionary dynamics of $B R C A 1$ alterations in breast tumorigenesis. J Theor Biol 273: 207-215, 2011.

31. Valentin MD, da Silva SD, Privat M, Alaoui-Jamali M and Bignon YJ: Molecular insights on basal-like breast cancer. Breast Cancer Res Treat 134: 21-30, 2012.

32. Warmoes M, Jaspers JE, Pham TV, et al: Proteomics of mouse BRCA1-deficient mammary tumors identifies DNA repair proteins with potential diagnostic and prognostic value in human breast cancer. Mol Cell Proteomics 11: M111.013334, 2012.

33. Esteller M, Silva JM, Dominguez G, et al: Promoter hypermethylation and $B R C A 1$ inactivation in sporadic breast and ovarian tumors. J Natl Cancer Inst 92: 564-569, 2000.

34. Rice JC, Ozcelik H, Maxeiner P, Andrulis I and Futscher BW: Methylation of the BRCAl promoter is associated with decreased $B R C A 1 \mathrm{mRNA}$ levels in clinical breast cancer specimens. Carcinogenesis 21: 1761-1765, 2000.

35. Krasteva ME, Bozhanov SS, Antov GG, Gospodinova ZI and Angelov SG: Breast cancer patients with hypermethylation in the promoter of $B R C A 1$ gene exhibit favorable clinical status. Neoplasma 59: 85-91, 2012.

36. Xu X, Gammon MD, Zhang Y, et al: BRCA1 promoter methylation is associated with increased mortality among women with breast cancer. Breast Cancer Res Treat 115: 397-404, 2009.

37. Matros E, Wang ZC, Lodeiro G, Miron A, Iglehart JD and Richardson AL: BRCA1 promoter methylation in sporadic breast tumors: relationship to gene expression profiles. Breast Cancer Res Treat 91: 179-186, 2005.

38. Li S, Rong M and Iacopetta B: DNA hypermethylation in breast cancer and its association with clinicopathological features. Cancer Lett 237: 272-280, 2006.

39. Krasteva ME, Bozhanov SS, Antov GG, Gospodinova ZI and Angelov SG: Breast cancer patients with hypermethylation in the promoter of $B R C A 1$ gene exhibit favorable clinical status. Neoplasma 59: 85-91, 2012. 